\title{
LA INTERDICCION CIVIL EN NUESTRO DERECHO
}

\section{Por JUAN I. REYNA}

La Interdicción Civil en nuestro Derecho se cuenta en el art. 32 del Código Penal, como accesoria de las penas de Internamiento, Penitenciarla y Relegación: priva, mientras se sufre la pena principal, de la patria potestad, de la representación marital que le conceden las leyes, y de la administración y disposición de sus bienes.

Esta disposición da lugar a que el condenado sea representado en el ejercicio de sus derechos civiles, por un curador, según las reglas que el Código Civil establece.

El citado artículo por las ventajas que de ellas resultan habría quedado más completo si estuviere redactado en la siguiente forma:

"La Interdicción Legal priva al penado del derecho de patria potestad, de la representación marital que le conceden las leyes, de la administración de sus bienes, y del derecho de disponer de ellos por acto entre vivos. El penado quedará sujeto a la curatela establecida por el Código Civil para los incapaces".

Ofrece más ventajas por las siguientes razones: "Interdicción Legal", porque precisa más su contenido, ya que ella deriva de la ley y no de una declaración judicial. "Por acto entre vivos", pues en esta forma aclara el concepto, en el sentido de que el penado puede disponer de sus bienes por acto de última voluntad, o sea, que puede testar, y finalmente "el penado quedará sujeto a la curatela establecida por el Código Civil para los incapaces", por dar más alcance a la citada disposición.

\section{NATURALEZA Y CARACTERES DE LA INTERDICCION}

ANTECEDENTES. - Nada concreto existe en nuestro Derecho que pueda servir como antecedente para el estudio de la Interdicción Civil. Aparte del Código Civil de Santa Cruz, que tuvo una existencia transitoria, nuestros códigos tanto Civil como Penal derogados, no contienen modificaciones sustanciales en lo que se refiere al punto que tratamos.

Aunque el Código de Santa Cruz como ya dijimos, rigió en forma transitoria, es interesante hacer notar su importancia en lo concerniente a esta institución. Si bien es verdad que el citado código es un calco del Código 
de Napoleón, es interesante, pues entre sus disposiciones se encuentra legislada la muerte civil, aunque algo atenuada.

En el capítulo III del aludido cuerpo, encontramos legislada la muerte civil con las consecuencias derivadas de ella. Así el art. 14 establece la muerte civil diciendo que es la condenación a penas, cuyo efecto es privar al condenado en toda participación de los derechos civiles. A continuación el art. siguiente dice que la condenación a muerte natural trae consigo la muerte civil.

No seguiremos paso a paso el articulado, bástenos decir que entre sus efectos, el , condenado no podía recibir por testamento ni por donación bienes algunos sino por causa de alimentos. No podía ser tutor ni concurrir a las operaciones relativas a la tutela, ni proceder judicialmente ni como demandante ni como demandado, sino bajo el nombre y por nuinisterio de un curador especial, que le será nombrado por el tribunal, ante quien está entablada la demanda. Pero podrá testar o dar para que otro teste a su nombre.

Nuestro código de 1852 no contemplaba entre sus disposiciones, la curatela para los que sufren la pena de interdicción civil, como lo hace el vigente, pero en cambio éste nada dice respecto a la facultad de poder testar el penado como lo disponía expresamente el código civil del ,52, y como lo consignaba aún el de Santa Cruz. El Código Penal de 1863, igualmente contiene una fórmula en su art. 83 mucho más precisa que la considerada en nuestro actual Código Penal.

\section{NATURALEZA Y CARACTERES DE LA INTERDICCION CIVIL}

Vamos a estudiar lo referente a los caracteres que presenta la institución en nuestro Derecho.

Del estudio de las diferentes legislaciones, se puede observar las diversas modalidades que ésta presenta. En unas la interdicción presenta la forma de una medida tutelar o de protección del penado, en otras adquiere un carácter represivo, y finalmente hay países en que esta interdicción no existe.

\section{PENA O MEDIDA DE PROTECCION}

La interdicción civil en nuestro código reviste el carácter de pena accesoria. Parece pueril tal afirmación, pero no lo es tanto, pues no todas las legislaciones presentan los mismos caracteres. 'Por oiro lado se sostiene que la interdicción civil en nuestra legislación adquiere la forma de una medida de protección, y esto 'por existir una institución tutelar, veladora de los intereses del penado, cual es la curatela para ellos establecida.

A primera vista parece que así fuera, pero después de analizar los dispositivos, veremos que no presenta tal carácter.

La interdicción civil como legisla nuestro Código Penal, es la consecuencia de las penas de Penitenciaría, Relegación o Internamiento; ellas traen consigo la ya citada interdicción. Luego establece en otra disposición que las penas de prisión no producen interdicción civil.

Vemos pues, que pará la imposición de la interdicción civil, nuestra legislación se atiene a la gravedad del delito. Si la interdicción tuviera 
como finalidad exclusiva el velar por los intereses del penado, no se explicaria esta diferencia por nuestra ley. Se admite que la curatela del penado se haga con el fin de conservar su patrimonio, y que en consecuencia, esa curatela tenga un objeto de protección. Pero de ahí a sostener que la interdicción civil (no la curatela) tenga un fin tutelar, hay mucha diferencia.

Hecha esta observación de la cual salta a la vista el carácter represivo que la interdicción civil presenta en nuestra ley, haremos hincapié en este mismo punto, pero en lo relativo a la curatela.

Las penas de Penitenciaría, Relegación o Internamiento, traen consigo la interdicción civil y como consecuencia la curatela. Lógico es pensar que si la pena de prisión no la produce, también lo es, que para ellos no se establezca esta institución.

Esta diferencia no tiene una explicación jurídica, pues la curatela se establece en beneficio de los que por su mayor peligrosidad son penados más severamente, dejando en desamparo a aquellos cuya pena es menor por ser menos grave el delito. A los primeros se les nombra un curador de oficio, a los segundos nó. Se aducirá que estos sufren la pena de Prisión; por lo mismo que no se les priva de sus derechos civiles, pueden ejercitarlos libremente por intermedio de un representante. Aceptamos tal afirmación. Pero ¿de qué le valdrá, si por la misma situación en que se encuentran, se hallan imposibilitados por la reclusión, de tener la libertad suficiente para controlar sus intereses? Por otro lado existen penados, y sobre todo los pertenecientes a la población indígena, que dada súi ignorancia descuidarían el designar a una persona que los representara, encargándose arbitrariamente sus familiares, si son personas capaces, de la administración de sus bienes.

Por estas razones nos parece conveniente que esta curatela se hiciese extensiva a los que sufren pena de prisión (adquiriendo el goce de sus derechos civiles con la libertad condicional), regularizando en esta forma su situación, haciéndolos partícipes de los beneficios de ḷa curatela, no ya solo en cuanto a las ventajas resultantes de ella, como sería la buena administración de sus bienes, sino también en lo concerniente al debido control legal que nuestras disposiciones exige al curador.

\section{DURACION DE LA INCAPACIDAD}

Continuando con el estudio de los caracteres de la interdicción civil, nos ocuparemos del término de duración de esta incapacidad. Esta la encontraremos en los arts. 31 y 34 del Código Penal, y art. 606 del Código Civil, que fijan la duración.

Aunque pequemos por falta de didáctica, pero siéndonos indispensable para el objeto que nos proponemos, reproduciremos : el texto del articulado:

El art. 31 del C. P. dice: La pena de internamiento más allá de un mínimun de veinticineo años llevará consigo la inhabilitación absoluta e interdicción civil "durante su cumplimiento" y la inhabiltación posterior que se establezca al conceder la libertad.

El mismo cuerpo de leyes en su art. 34 dispone lo siguiente: Las penas de penitenciaría y de relegación llevarán consigo la inhabilitación absoluta e interdicción civil "durante la condena" y la inhabilitación pos- 
terior que establezca la, sentencia.

Y finalmente el art. 606 del C. C. establece que la curatela del condenado a una pena privativa de la libertad acaba al mismo tiempo que la prisión.

Como se desprende de los artículos enumerados, la duración de la incapacidad del penado no va más allá del fijado por la pena, ni menos como lo sería el caso de la libertad condicional, de la que nos ocuparemos más adelante. Los términos del art. 31 "durante su cumplimiento". los del art. 34 "durante la condena". así como los del art. 606 del C. C. "acaba al mismo tiempo que la prisión", nos están indicando con claridad la duración de esta incapacidad.

\section{SITUACION DEL PENADO EN LIBERTAD CONDICIONAL}

Punto interesante es éste, ya que se relaciona con la duración de la incapacidad. Como hemos visto nuestros códigos establecen la duración de la interdicción civil, y aunque no hay lugar a interpretación respecto a la situación del penado en libertad condicional, ya que el art. 606 del C. C. en su segundo aparte, dice que "el penado liberado condicionalmente continúa bajo curatela", es interesante, pues la citada disposición hace resaltår más el carácter de pena que en nuestro Derecho tiene la interdicción civil, pues si ella estuviese establecida únicamente como se sostiene atendiendo a la falta de libertad del penado, no se explicaría que éste continuase bajo curatela, gozando de la libertad condicional, y por lo tanto, facultado para poder ejercer libremente sus derechos.

Al respecto se ha suscitado divergencias, si bien es verdad que las doctrinas francesa e italiana, han admitido uniformemente que la capacidad dura mientras dure la pena; que la libertad condicional no extingue la pena, sino que es una forma de seguir cumpliéndola, y por lo tanto no cesa por ello la interdicción del condenado. Otros autores estudiando la libertad condicional y las condiciones necesarias para que ella de los resultados que se esperan, establecen los siguientes principios: a).- Ante todo se necesita que el liberado sea preparado por el régimen penitenciario, a desenvolver en la sociedąd una actividad honesta y laboriosa. La libertad condicional no puede ser la base de un sistema penitenciario, sino su coronamiento. Esta institución es una de las penas de conjunto del régimen progresivo en el cual el detenido pasa por una serie de pruebas antes de ser puesto definitivamente en libertad. b).-Que es necesario que la liberación tenga por complemento el concurso de un patronato en el cual el liberado encontrará un apoyo material y moral, para rehabilitarse. c).La libertad condicional es una institución fracasada si ella no es acompanada de una vigilancia severa e incesante sobre la conducta de los condenados que obtienen su beneficio.

Pero no obstante estos argumentos bien fundados, existen otros que igualmente no carecen de valor. Se dice que la finalidad de la liberación condicional exige que la persona acreedora a ese bèneficio cuente con los elementos y facultades normales de que dispone una persona libre; por su buena conducta mientras ha sufrido la privación de la libertad, se le levanta esa privación para que se empeñe en reconstruir su vida. Si tiene bienes, le servirán de eficaz auxilio; sı tiene familia, debe volver al seno de ella 
para reasumir sus funciones paternas y maritales. Si se le priva del derecho de administrar sus bienes y de disponer de ellos, cada vez que necesite concertar el más insignificante contrato, tendrá que procurarse el con. curso de su curador con la consiguiente vejación moral y el discrédito irre. mediable aparejado a una semejante interdicción. Eso sería una persecum ción "usque ad saccum et peram", adversa a los propósitos a que respond'e la libertad condicional.

Estos principios nos parecen acordes con los derechos humanos. El penado estaría en una situación muy triste, al no poder ejercer aún aquellos derechos tan inherentes a la persona, como son los de patria potestad y autoridad marital. Nos parecería más justo, que al penado en libertad condicional se le concediese estos derechos ya que ellos importan situacio. nes que vendrían a favorecer los fines que persigue la libertad condicional.

\section{FORMAS EXTINTIVAS DE LA INTERDICCION CIVIL.-EL INDULTO}

Algunos enumeran entre las causas de extmción de la pena como la principal, el cumplimiento de la misma, en virtud del principio comúnmente aceptado que la pena extingue el delito y por consiguiente la interdicción civil.

Existen otras formas como son la muerte del penado, principio que se considera axiomático desde que el Derecho penal de la Revolución Francesa proclamó la responsabilidad exclusivamente personal del delincuente. El Derecho penal, a partir de esta época, declara como un dogmá fundamental el principio de la personalidad de la pena, por tanto, la muerte del penado extingue la pena. Acerca de este punto no hay discusión.

Pero entre otras, la forma más típica de extinción, es el indulto, ya que el mismo hace cesar las incapacidades, porque de acuerdo con el art. 126 del Código Penal, "la amnistía suprime legalmente el hecho punible a que se refiere e implica el perpetuo silencio respecto de él, y agrega luego, el indulto suprime la represión del hecho punible", suprimiendo co" mo es natural los efectos de la interdicción civil.

Estos conceptos están robustecidos por lo dispuesto en el art. 13 del Código de Comercio, que dice que no podrán ejercer el comercio ni tener cargo ni intervención directa, administrativa o económica en las compañías mercantiles o industriales, los sentenciados a penas de interdicción civil, mientras" no hayan cumplido sus condenas o sido amnistiados o indultados.

Esta disposición faculta pues, al penado que haya sido indultado a poder ejercer el comercio, admitiendo como es lógico la extinción de la incapacidad derivada de la interdicción civil, ya que el indulto suprime el hecho punible y como corolario la interdicción que lleva anexa.

\section{SITUACION JURIDICA DEL PENADO.-CLASE DE INCAPACIDAD DE QUE ADOLECE}

Las incapacidades de hecho son de dos clases: absolutas y re lativas. Las primeras inhabilitan a la persona para el ejercicio de todos sus derechos, por las segundas, el incapaz es privado del ejercicio de cier. tos derechos, o ese ejercicio queda condicionado a ciertos requisitos. 
Nuestro Código Civil establece en el título réspectivo, ambas incapacidades: la absoluta y la relativa.

Las incapacidades de derecho, no se encuentran en un título único; son siempre de carácter especial, y se encuentran diseminadas.

El art. 9 del Código Civil, enumera las personas que sufren de incapacidad absoluta, tales son: $1^{\circ}$ - Los menores de 16 años; $2^{\circ}$ - Los que adolecen de enfermedad mental que los priva de discernimiento; $3^{\circ}$--Los sordomudos que no saben expresar su voluntad de una manera indubitable; $4^{\circ}$ - Los desaparecidos cuya ausencia está declarada judicialmente.

La incapacidad relativa la establece en el art. siguiente que dice: "Son relativamente incapaces los mayores de 16 años, $y$. los sujetos a curatela no comprendidos en el artículo anterior".

Como se desprende del articulado, nuestro Código sitúa entre las disposiciones referentes a la incapacidad de las personas, la que surge de una condena criminal. Los efectos de esta incapacidad se hallan concretados en el Código Penal en su art. 32, pero esta disposición, nos senala limitaciones que en su capacidad sufre, pero no ubica la situación jurílica del penado.

Esta ubicación la encontraremos, como ya hemos visto, en el art. 10 del C. C., pues del contenido del citado dispositivo se desprende que los penados se encuentran en la misma situación que los mayores de 16 años, ya que al decir el artículo que comentamos, "y los sujetos a curatela no comprendidos en el artículo, anterior" esta reconociendo la igualdad de situación entre éstos y aquellos, y por tanto incluyendo dentro de la citada disposición a los penados, ya que estos están bajo curatela conforme al titulo $\mathrm{V}$, art. 587 , establecida para los que sufren la pena de interdicción civil; y esta curatela no se encuentra comprendida dentro de las que es. tablece el art. 9 del C. C.. El citado artículo involucra, pues, al penado dentro de él, considerándolo como relativamente incapaz, y estableciendo en consecuencia, que la incapacidad de que adolece, es una incapacidad relativa de hecho.

Al respecto, el profesor argentino Valdés, dice que la interdicción impuesta a raíz de una condena criminal no está determinada por causas iguales o equivalentes a las que originan la incapacidad absoluta de obrar, puesto que al penado no tiene los impedimentos físicos y morales que esta incapacidad presupone. Luego ha de admitirse que la interdic. ción legal constituye una incapacidad relativa de hecho, semejante a la del "menor adulto", en cuanto ambas contienen restricciones importantes a una representación necesaria, aunque difieren ostensiblemente en sus fundamentos y alcances.

\section{F.FECTOS DE LA INTERDICCION CIVIL}

\section{PATRIA POTESTAD.}

Los derechos de los que se priva al condenado, como consecuencia de la Interdicción Civil, se hallan taxativamente enumerados en el art. 32 del C. P. y se limitan, por tanto, a la privación por el tiempo de la condena: $1^{\circ}$ - de la patria potestad; $2^{\circ}$ - de la representación marital que le conceden las leyes; $3^{\circ}$ - de la administración y disposición de sus 


\section{bienes.}

Nos ocuparemos, pues, a continuación de la patria potestad, y diremos que por ella los padres tienen el deber y el derecho de cuidar de la persona y bienes de sus hijos menores (art. 390 C. C.). La patria po: testad es pues, el conjunto de relaciones que la ley concede al padre y a la madre sobre la persona y bienes de sus hijos para facilitar el cumplimiento de los deberes de alimentación y educación a que están obligados.

Establecidos estos conceptos, estudiaremos esta incapacidad en su naturaleza y efectos.

La privación de la patria potestad, se ha admitido que es una consecuencia lógica de la doble incapacidad que tiene el penado de ad. ministrar sus propios bienes; incapacidad que lógicamente le impedirá también administrar los bienes de sus hijos.

Se admite también, que esta medida toma un carácter de sanción para el padre, al privársele aún de aquellos derechos que con respecto a sus hijos menores, podría ejercer desde el aislamiento de su prisión. A más que la privación de este derecho, se produce de hecho, pues basta la simple pena impuesta para que tenga su efecto, a diferencia de las demás causas de la pérdida de la patria potestad, que deben ser declaradas expresamente.

La privación de la patria potestad trae consigo, asi mismo la de todos los derechos sobre las personas y bienes de sus hijos, así como también, el dar el consentimiento de matrimonio, el de designarles tutor testamentario, el usufructo legal de los bienes de sus hijos, etc. Pero esto de ser privado de la patria potestad, no significa la exoneración de las obligaciones, cuyo cumplimiento sea compatible con el estado de reclusión.

\section{SUSPENSION, PRIVACION, PERDIDA DE LA PATRIA POTESTAD.}

Por la forma en que se halla redactado el artículo 32 del Código Penal la citada disposición implica una privación, pues ella dice: Por la interdicción civil "se priva" del derecho de lá patria potestad. Pues es sabido que terminado el plazo de la pena, el padre recobra el ejercicio de sus derechos sobre sus hijos.

Y hago en este punto hincapié, pues el art. 427 del Código Civil, no está conforme con el art. 32 del C. P. en cuanto a los términos que emplea, pues este último usa privación y el anterior pérdida. Ya hemos visto que el art. 32 del C. P. dice: "Por la interdicción civil se priva del derecho de patria potestad", y luego el C. C. en su' art. 427 declara: La patria potestad se pierde por condenación a penas que produzcan tal efecto. Por otro lado el art. 432 del C. C., que se refiere' a la suspensión de la patria potestad, en su inciso $3^{\circ}$, dispone que se suspende la patria potestad por la Interdición Civil. A propósito, el término Interdicción Civil, debería ser sustituído por el término más expresivo de Interdicción Legal, ya que la interdicción civil tiene un sentido más amplio, más genérico, pues dentro de él, puede involucrarse a los pródigos, a los ebrios habituales, etc. Esta interdicción se declara a pedido de parte, en cambio la interdicción del condenado deriva de la misma ley, de la condena, no es necesario que sea pedida, sino que es el resultado de la misma. Es por eso 
que debería emplearse, el término de interdicción legal, pues ella se ajusta más a su sentido, especificándola.

El art. 434 del C. C. nos está indicando que es una suspensión, al igual que el art. 32 del C. $P$. 'que priva de este derecho mientras dure el tiempo de la condena, terminada ésta, el penado vuelve a recobrar el ejercicio de la patria potestad, sin más declaración que la extinción misma de la pena.

\section{AUTORIDAD MARITAL.}

Continuando con el estudio del tantas veces citado art. 32 del C. P., vá que él establece los derechos de los que se ven privados los penados. nos referiremos a otro de ellos; al de la representación marital que le conceden* las leyes.

Según lo dispuesto por nuestro Código Civil, el marido es el representante legal de la sociedad conyugal, él es quien la dirige, a él le compete fijar y mudar el domicilio de la familia, así como decidir sobre lo referente a su economía (arts. 161, 162, 168, C. C.).

La disposición contemplada en nuestro Código de Procedimientos Civiles, en su art. 20, que concède al marido la facultad de ejercer en juicio la representación de la mujer, ha quedado derogada por el actual $C$. $C$. en su art. 172, segundo aparte, que dice: la mujer puede comparecer en juicio, pudiendo en consecuencia comparecer sin autorización del raarido.

La autoridad marital ha quedado en muchos casos limitada. Por ejemplo, la mujer en principio no puede ejercer profesión o industria, o efectuar cualquier trabajo fuera de la casa común sin el consentimiento expreso o tácito del marido, pero si éste se negase, podrá ser autorizada por el juez, siempre que pruebe que esta medida lá justifique el interés de la familia (art. 173 C. C.).

Hemos la relación de estos derechos que la ley concede al marido, ya que la interdicción civil importa la negación de todos ellos, siendo la mujer según lo establecido por el art. 174 del C. C. la que asumirá la dirección y representación de la sociedad conyugal, cuando el marido haya sido condenado a una pena privativa de la libertad que produzcá la interdicción civil, estando facultada por idénticas razones a poder ejercer libremente el comercio (art. I I, C. de C.).

\section{ADMINISTRACION Y DISPOSICION DE SUS BIENES}

Trataremos a continuación, finalmente, de la administración y disposición de sus bienes, derecho del que se ve privado igualmente èl penado como resultado de la Interdicción Civil.

\section{CURATELA}

Nuestro Código Penal al privar al penado de este derecho, prevé también la situación que esta disposición le ocasiona, y al efecto le nombra un curador, encargado de la administración de sus bienes y de su representación en juicio. 
Esta institución veladora de los intereses del penado, no existía en el Código Civil derogado, como lo consigna en un título especial el actual Código del 36, si bien es verdad, que la Ley 2142, del 6 de Oc. tubre de 1915, contempla la situación de los penados en cuanto a la guarda de sus bienes, pues la citada Ley en su artículo único disponía lo siguiente: La guarda de los bienes pertenecientes a los condenados a la pena de interdicción civil, corresponde a las personas designadas en el art. 29 y siguientes del Código de Procedimientos en la materia.

Como vemos ya se encuentra el penado bajo una disposición que lo ampara, pero nuestro actual código civil, legisla en la debida forma esta zituación, como apreciaremos en las siguientes líneas.

$\mathrm{El}$ art. 587 del C. C. dice que ejecutoriada la sentencia que lleve consigo la interdicción civil, el fiscal pedirá inmediatamente el nombramiento de un curador. Si no lo hiciere será responsable de los daños y perjuicios que sobrevengan. También pueden pedir el nombramiento de un curador el cónyuge y los parientes del interdicto.

\section{¿A QUIENES CORRESPONDE ESTA CURATELA?}

A continuación el art. 588 dispone que la curatela se defiere por el orden establecido en el art. 559, o sea que corresponde a las siguientes personas: $1^{\circ}$-Al cónyuge no separado judicialmente; $2^{\circ}-\mathrm{A}$ los padres; $3^{\circ}$. A los descendientes, prefiriéndose el más próximo al más remoto $\mathrm{y}$, en igualdad dé grado, al más idóneo. La preferencia la decidirá el juez, oyendo al consejo de familia; $4^{\circ}$ - A los abuelos. y demás ascendientes, regulándose la designación conforme al inciso anterior.

\section{FUNCIONAMIENTO}

Esta curatela se limitará a tenor del art. 588, a la administración de sus bienes y a la representación en juicio del penado. La función pues, del curadór se reducirá a velar por la buena marcha de sus negocios, es decir que solamente puede ejecutar los actos administrativos de custodia y conservación.

El penado en consecuencia no puede ejercer acto alguno de administración y disposición de sus bienes. Esas funciones las va a realizar su curador.

Esta curatela debe regirse, como lo dispone el art. 558 del C. C. por las reglas relativas a la tutela, con las modificaciones establecidas. de la tutela.

Es decir que se aplicarán en cuanto sean compatibles con las reglas

Por consiguiente el curador, si no es legítimo deberá constituir hipoteca o prenda o prestará fianza si le fuere imposible dar alguna de esas garantías para asegurar la responsabilidad de su administración (art. 499 C. C.). Tratándose del curador legítimo, éste no estará obligado a dar garantías, salvo que el juez resuelva que la constituya por requerirlo así las circunstancias.

Deberá también el curador antes de encargarse de la administración, practicar inventario judicial (art. 503 C. C.). 
El curador pues, estará sometido a todas las reglas de la tutela. No podrá enajenar los bienes' del penado, ni gravarlos, sino con licencia judicial, concedida por necesidad o por utilidad manifiesta. En fin, se sujetará a todo lo dispuesto por la ley para estos casos, debiendo, al cesar la curatela, por obligación, daŕ cuenta de su administración, si es el curador legítimo, o anualmente si no lo es (arts. 530, 531 C. C.).

En términos generales el penado, como consecuencia de la interdicción civil, no podrá ejercer acto alguno de administración o disposición de sus bienes, tampoco comparecer en juicio; estas funciones las realizará su curador.

\section{INCAPACIDADES ESPECIALES}

Estas incapacidades de carácter especial igualmente se encuentran esparcidas en los diferentes títulos de nuestro Código Civil y algunas de ellas en el Código de Comercio.

Aún cuando su artálisis no pertenece a la naturaleza de este estudio, conviene tratarlas por estar relacionadas con la materia.

\section{TUTELA}

Continuando con el estudio de las incapacidades, tócanos ocuparnos de las especiales, entre las que se encuentra la Tutela.

Nuestro Código Civil en su art. 490, inciso $8^{\circ}$ establece que son inhábiles para eer tutores, "los condenados por homicidio o por delitos contra el patrimonio o contra las buenas costumbres"; es decir los que hubiesen sido penados por homicidio o por delitos de robo, estafa, falsedad, corrupción de menores, etc., infracciones que hacen presumir en quién fué responsable de ellas por condena, de una manifiesta falta de condiciones morales para el buen, ejercicio de la tutela.

Las mismas razones que imponen la pérdida de la patria potestad, determinan la incapacidad del condenado para ser tutor o curador, y como consecuencia, la caducidad de la tutela o curatela que él ejerciere.

La condena importa la incapacidad perpetua del individuo para el ejerçicio del cargo de tutor, y no sólo la suspensión del mismo. Se diferencia así del caso de la patria potestad cuyo ejercicio puede ser recuperado por el padre; si se hubiera rehabilitado, como consecuencia de una consideración especial de la ley a la paternidad y a la institución de la familia.

\section{INCAPACIDAD MATRIMONLAL}

En materia de matrimonio, existe como incapacidad o impedimento para contraer el mismo, la de la persona condenada como partícipe en la muerte de uno de los cónyuges, ni el procesado por esta causa, con el sobreviviente (art. 82, inc. 4, C. C.).

Como en el caso anterior, es necesario que haya condena y que el delito hubiere sido voluntario. 
Consumado el homicidio, sostiene, el Dr. Oliveira, que el impedimento de crimen existe, aún cuando el homicida no haya cometido adulterio con el otro cónyuge, ni haya conspirado con él contra la vida de la víctima. En vista de su pretensión matrimonial, se presume, con presunción juris et de jure, que el móvil del crimen fué remover el obstáculo legal que se oponía a la celebración del matrimonio. Verdad es que los hechos pueden estar en contra de esta presunción, pues el móvil del crimen puede haber sido otro, por ejemplo el robo, la venganza, pero, aún en estos casos, el impedimento se justifica, por razones que impone la moral. No coincide con la expuesta la doctrina canónica, de la que se apartaron ya, en parte. nuestros codificadores, pues el Código no innova. Ella está resumida en el cánon 1075, expuesto así por el jesuíta Ferreres: "Tampoco pueden. contraer matrimonio válidamente entre sí si uno de ellos mató al otro cónyuge... El mismo impedimento de crimen hace nulo el matrimonio entre aquellos que con mutua conspiración dieron muerte a uno de ellos, aunque no haya mediado el adulterio". De esta doctrina que penetra en el dominio de las intenciones, quedan raros ejemplares en el campo del derecho comparado. Entre ellos nos es dado citar el art. 17 inc. 6 de la novísima ley mexicana de Relaciones Familiares que dispone lo siguiente: "son impedimentos para celebrar matrimonio el atentado contra la vida de alguno de los casados para casarse con ei que queda libre"."

\section{INCAPACIDAD SUCESORIA}

Esta incapacidad especial se halla sancionada en el art. 665, inc. $1^{\circ}$ del Código Civil, y dice así:" Son incapaces para suceder a determinadas personas como herederos o legatarios por causa de.indignidad: $1^{\circ}$ Los autores o partícipes de atentado contra la vida del causante, de su cónyuge, descendientes, ascendientes o herederos." Esta indignidad no queda sin efecto por el indulto ni por ia prescripción".

Como se ve en este primer inciso, el hecho que origina la indignidad es el atentado contra la vida del causante, de su cónyuge, descendientes, ascendientes o herederos, y se comprende tanto el caso del homicidio cuanto el de la simple tentativa. El que atenta contra la vida de su causante, es indigno, como autor o como cómplice, porque la unidad delictual en este caso, hace que se confunda la persona del autor directo con la del simple cómplice. La razón de este inciso como la de otros, es de que existe una reunión de sentimientos de orden moral que hacen inconcebible que pueda heredarse a alguien contra cuya vida se ha atentado. La ley, entonces, atendiendo a estas razones, los excluye de la herencia.

Surge de la ley, que en estos casos debe haber una senterria o condena si se trata de un delito consumado o tentativa, pero si el atentado contra la vida del causante es excusable, entonces no se aplica el precepto legal, porque establece una relación con lo que dispone el Código Penal en el título referente al estado de necesidad.

El Código Civil agrega que la indignidad declarada anteriormente, se aplica siempre aún cuando haya quedado sin efecto la sentencia de indulto o por prescripción. Como consecuencia de estos casos la indignidad declarada impide heredar. Aquí se ve una diferencia entre el concepto civil y el concepto penal. Conforme al Código Penal el indultado o aquel cuyo delito ha prescrito, queda al margen de la ley, pero el indulto ni la 
prescripción borran el delito cometido, lo que borran es simplemente la pena, entonces el derecho establece que siempre existe el delito de parte del causahabiente, motivo por el cual en el Derecho Civil funcionan las reglas de indignidad.

El siguiente inciso o sea el $2^{\circ}$ del art. 665, indica asimismo a las personas que se han hecho acreedoras por sus actos delictuosos a esta sanción, es decir a ser excluídas del derecho hereditario. El inciso $1^{\circ}$ del que nos hemos ocupado ya, no ofrece mayor dificultad en su interpretación, pero el presente, merece mayor observación, dada la complejidad de su redacción.

El indicado inciso excluye, como textualmente dice la letra, a los autores o partícipes de delitos comprendidos en los Títulos I, II, y IV de la Sección Primera y en las Secciones Segunda y Tercera del Libro Segundo del Código Penal.

Para mayor claridad indicaremos cuáles son estos delitos. Los tím tulos I, II, y IV de la Sección Primera se ocupan respectivamente de los Delitos contra la vida, el cuerpo y la salud (arts. 150 y sgts.); de las lesiones (art. 165 y sgtes.), y por último de la Riña (art. 169 y sgtes.).

Luego se refiere a las Secciones Segunda y Tercera del Libro Ser gundo, las que se ocupan en su orden de los Delitos contra el Honor y contra las buenas costumbres.

Hemos hecho la relación detallada de estos delitos, ya que este precepto nos parece un tanto exótico, que no se encuentra en otras leyes y encierra un principio de vastos alcances. Según esta disposición aquel que comete cualquier delito, quedará en la imposibilidad de heredar. Pero los legisladores no han querido referirse a aquéllos que cometen un delito contra cualquiera clase de persona, sino al caso del que comete un delito contra su causante, pero esta es una interpretación que no resulta del Código, pero hay que aceptar que el art. 665 inc. $2^{\circ}$, se refiere a aquel que comete un delito contra la persona del causante, sea este una injuria. P'ero de todas maneras la sanción impuesta tiene grandes proyecciones.

\section{DESHEREDACION}

Asimismo la desheredación opera en este caso, haciendo incapaz para suceder al que haya sido condenado a sufrir una pena que lleva consigo la Interdicción Civil, como lo expresa el art. 713 del Código Civil en su inciso $3^{\circ}$ Esta incapacidad tiene lugar siempre que la causa esté expre.. samente invocada en el testamento.

\section{SITUACIONES JURIDICAS QUE SE PRESENTAN}

Dentro 'de la parte referente, debiéramos haber planteado estas situaciones, pero por ofrecer especial interés, hemos querido tratar por separado estos aspectos legales que se derivan del estado jurídico del penado.

\section{¿PUEDE El PENADO TESTAR?}

El Dr. Cornejo en su comentario al Código Penal, dice que la ley 
al privar al condenado de la disposición de sus bienes lo priva también de la facultad de poder testar, contrariando la idea tutelar que se convierte en una pena injusta para la familia. El legislador ha debido reconocer expresamente este caso y admitir en todo momento el derecho de testamentifacción", como lo hacía nuestro derogado Código Civil del 52, que lejos de prohibirlo lo facilitaba proporcionando una fórmula especial para otor. garlo en caso de necesidad, en su art. 680 , que decía lo siguiente: "Si el testador se halla preso, podría en caso de necesidad, otorgar su testamento ante el jefe de la prisión; pudiendo ser testigos, a falta de otros, los detenidos o presos, con tal que no sean inhábiles por otras causas. En este testamento es nula cualquiera disposición a favor de los que tienen autoridad en la prisión, a menos que sean parientes del testador dentro del cuarto grado".

Como vemos esta disposición referente al derecho de testamentifacción no ha sido considerada en nuestro nuevo Código Civil, como lo hacía el anterior, pero si bien se admite unánimemente que la pena no puede extenderse a la familia, una disposición expresa podría resolver cualquiera mala interpretación que surgiera al respecto. Por otro lado existe en nuestro Código Penal de 1863, una disposición que hubiera sido ventajoso conservar en el actual, pues establecía una norma más completa en lo que se refiere a la Interdicción, ya que en su art. 83 , indicando los derechos de los que se privaba al penado, entre otros, decía: se priva al penado de la administración de sus bienes y del derecho de disponer de ellos por acto inter-vivos, salvo los casos en que la ley limita estos efectos.

Esta disposición completa, mas aún esta situación, ya que al decir "por acto inter-vivos", está facultando al penado a poder otorgar su testamento.

Pero por otra parte, los efectos jurídicos de un testámento vienen a producirse como es natural a la muerte del penado, circunstancias, que como es lógico hacen desaparecer la posible incapacidad, ó de otro lado, los efectos de esta disposición se producirían recién al fallecimiento del penado, oportunidad en que cesa la curatela.

Si aceptáramos esta incapacidad, estaríamos volviendo en buena forma a la ya abolida muerte civil, pues sería hacer extensiva esta sanción a la familia, que no tiene porqué sufrir sus consecuencias.

\section{ACTOS REALIZADOS POR EL PENADO}

Por lo dispuesto en el art. 32 del C. P., el penado se ve privado entre otros derechos, del de poder administrax y disponer de sus bienes.

Ahora, cabe preguntarnos: ¿Los actos jurídicos realizados por los penados son válidos?. Lógico es que si no gozan de la capacidad suficiente, tampoco lo sean. Un contrato hecho por un penado que se encuentra bajo libertad condicional, sin intervención de su curador, no sería nulo, como algunos sostienen, sino simplemente anulable; es decir, que tendrá valor mientras no quede ejecutoriada la sentencia que lo invalide.

$Y$ decimos que los actos jurídicos son anulables y no nulos, pues a tenor del art. 1125 del C. C., que dice que el acto jurídico es anulable: 1 - Por la incapacidad relativa del agente. El penado, como se deduce del art. 10 del mismo código, tiene incapacidad relativa. Dicho art. involucra, como hemos visto, al tratar de la situación jurídica del penado, 
a este considerándolo relativamente incapaz y siendo, por consiguiente, los actos realizados por él simplemente anulables, y no nulos.

\section{¿PUEDE EL PENADO CONTRAER MATRIMONIO? - ¿PUEDE RECONOCER UN HIJO?}

Nuestra legislación nada dice acerca de si el penado puede o nó contraer matrimonio, pero si bien se admite doctrinariamente que puede hacerlo, ya que si la reclusión en que se encuentra es incompatible con los fines del matrimonio, el penado podría efectuarlo por legalizar una situación irregular resultante del concubinato, y dando asimismo a sus hijos la calidad de legítimos, hecho que redundaría en forma indiscutible en beneficio del orden social y familiar.

Nuestros dispositivos legales que limitan su capacidad, no incluyen dentro de ellos, este derecho, suponiendo por tanto, que no hay impedimento para poder realizarlo.

Lo mismo podríamos decir tratándose del reconocimiento de un hijo natural, o del acéptar o repudiar la legitimación que de él hicieren sus padres, actos que se han reconocido con carácter de unanimidad en las legislaciones, por importar situaciones que la ley antes de obstaculizar debería ampararlas por contribuir a los fines que persigue.

\section{COMPARECENCIA}

Otra situación interesante es la siguiente: entablada demanda de divorcio contra el penado éste no podrá concurrir. El art. 588 del C. C. dice: el curador representa en juicio al penado.

Pero una situación de esta naturaleza, no surtiría los mismos efectos si el curador representara como le corresponde, al penado, pues el comparendo es acto en este caso, de carácter muý personal, y uno de los fines. que se persigue es la reconciliación, y ella no traería los mismos resultados, si es otra la persona que comparece. (Ver Ejecutoria Suprema inserta en la Revista de los Tribunales. Año 1931, pág. 2). 